\title{
Interferometric Path Models for GNSS Ground-Based Phase Altimetry
}

\author{
S. Khajeh ${ }^{1 *}$, A. A. Ardalan ${ }^{1}$, H. Schuh ${ }^{2}$ \\ ${ }^{1}$ School of Surveying and Geospatial engineering, Faculty of Engineering, University of Tehran, Iran-(Saman_khajeh, Ardalan)@ut.ac.ir \\ ${ }^{2}$ Department 1 Geodesy, GFZ German Research Centre for Geosciences, Potsdam, Germany-harald.schuh@gfz-potsdam.de
}

KEY WORDS: GNSS, Reflectometry, Altimetry, Planar Model, Tropospheric Correction, Ray-Tracing.

\begin{abstract}
:
Altimetry by using GNSS (Global Navigation Satellite Systems) reflectometry is regarded as a new promising technique. One important step to utilize this technique is modeling the interferometric path (the difference between the direct and the reflected signal paths). This paper evaluates three models: the planar model, the planar model with tropospheric correction and a model based on ray-tracing. If decimeter level accuracy for water surface fluctuation is required, the planar model cannot be used when a receiver is at an altitude of a few hundred meters and observations are taken at low elevation angles. On the other hand, depending on the mapping function and zenith total delay in the tropospheric correction, the planar model with tropospheric correction can provide decimeter level accuracy for low altitude stations. If simulated observations with a $1 \mathrm{~cm}$ accuracy have been employed to estimate Sea Surface Height (SSH) by the model based on ray-tracing the numerical results present $1 \mathrm{~cm}$ as RMSE for phase retrieval and $5 \mathrm{~cm}$ for Doppler retrieval. The planar model with tropospheric correction does not yield RMSE better than some decimeters for the same condition.
\end{abstract}

\section{INTRODUCTION}

Sea level fluctuations have been monitored for a very long time. Many techniques and instruments have been employed and each one has its own benefits. The first experiments were using the coastal tide gauges, which can provide sea level variations just for the coastal lines. With the rise of satellite geodesy, satellite radar altimetry techniques upgraded the global knowledge about the oceans. However, this technique suffers from the low quality observations at the coastal lines (Khajeh, Jazireeyan et al. 2014, Wickert, Cardellach et al. 2016). The potential of water level altimetry by using GNSS signals that are reflected off the water surface was first proposed by (Martin-Neira 1993) and introduced as a new bi-static technique that is called GNSS Reflectometry (GNSS-R). This technique makes use of reflected GNSS signals, called multipath in regular positioning (Bilich, Larson et al. 2004). By differentiating the reflected and the direct signal paths, which is called interferometric path in this study, the altitude between the receiver and the reflecting surface can be derived. After publishing the idea of GNSS-R many efforts have been made in order to explore this technique like detecting sea (Lowe, Zuffada et al. 2002, Ruffini, Soulat et al. 2004, Löfgren, Haas et al. 2011, Semmling, Beyerle et al. 2011) and lake (Treuhaft, Lowe et al. 2001, Helm 2008, Roussel, Frappart et al. 2014) water level changes.

In GNSS phase altimetry for the estimation of instantaneous sea level height, an accurate interferometric path model is a prerequisite (Martin-Neira, Caparrini et al. 2001). In this study, we utilize and evaluate the performance of three interferometric path models. The first one is the planar model (Helm 2008). This model can be considered the simplest but also most inaccurate one. The second model is the planar model with tropospheric correction (Cardellach, Fabra et al. 2011). This model takes into account that the direct (reflected) signals traverse the troposphere. Finally, the third model is based on ray-tracing (Semmling, Leister et al. 2016). The purpose of this paper is comparing these three models at a ground-based station at different altitudes nearby the coastline. We note that ionospheric effects are not considered in this study.

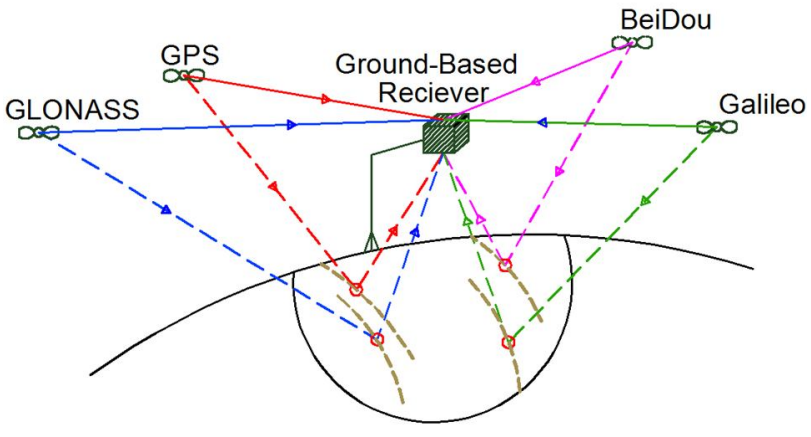

Figure 1: The concept of GNSS Reflectometry as a bi-static system including various satellite navigation systems like GPS, GLONASS, BeiDou and Galileo. The continuous lines are direct signals and the dashed lines are reflected. The brown dashed lines are the reflection points on the water surface. The interferometric path is the difference between reflected and direct signals paths.

Observations used in GNSS-R are code and phase measurements. The code observation cannot provide an accuracy better than several meters (Martin-Neira, Caparrini et al. 2001). In the case of phase observations the phase ambiguity, which can be assumed constant for a continuously tracked satellite, has to be estimated as an unknown parameter. This introduces correlation between the estimated phase ambiguity and the water level height. On the contrary, the Doppler retrieval does have no ambiguity but is sensitive to noises. Both simulated phase and Doppler observations are used in this study where, we make use of simulated observations that are generated by the raytracing with adding random noise.

\footnotetext{
* Saman Khajeh
} 
In the following sections, the utilized dataset is introduced. Then the model limitations and benefits are explored. The numerical results of using the phase and Doppler simulated observations under various conditions are presented in section 6 . The conclusions are given in section 7 .

\section{SIMULATED OBSERVATIONS AND CASE STUDY}

Fig. 2 illustrates the location and the geometry position of the assumed receiver antenna at Godhavn/Disko Bay schematically. The top panel shows the receiver position in Disko Bay. That is mountained at Lat:69.2716 $\mathrm{N}$, Lon:53.5434 $\mathrm{W}$. The observations are simulated at the altitudes of $691.62 \mathrm{~m}$ and $100 \mathrm{~m}$ above Mean Sea Level (MSL). A GNSS-R campaign was set up by GFZ (German Research Centre for Geosciences) at this particular station and at the altitudes if $691.62 \mathrm{~m}$ for about seven months (November 2008-May 2009) (Semmling 2012). The middle panel illustrates the footprint of the received signals through half an hour, and the lower panel shows the direct and the reflected signal path geometrically.

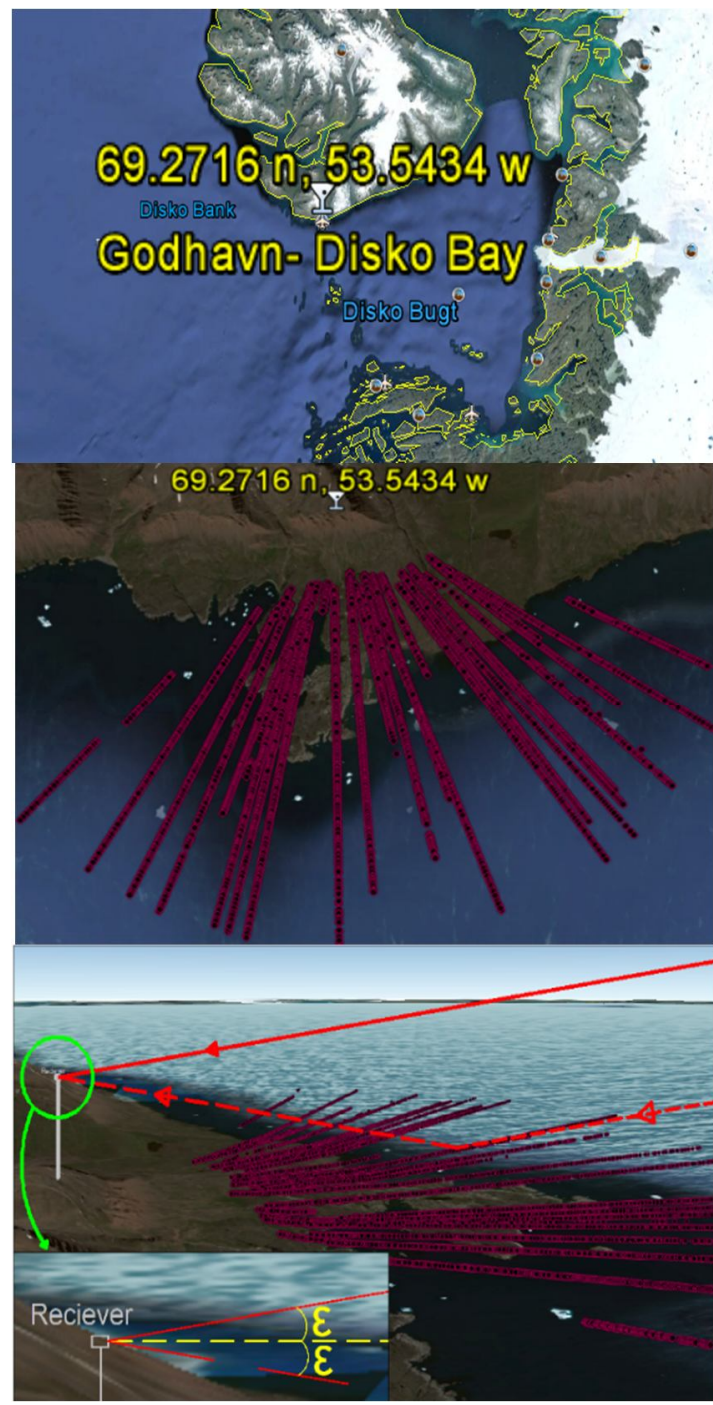

Figure 2: The location of the receiver antenna at Godhavn with an altitude of $691.62 \mathrm{~m}$. The top panel shows the location of the case study. The middle panel shows the reflecting point locations and the lower panel shows the geometric position of direct (continuous red line) and reflected (dashed red line) signals. $\varepsilon$ is the elevation angle of satellite.

\section{THE PLANAR MODEL}

The planar model represents the simplest option in order to estimate the water level height and can be written as (Helm 2008):

$$
I=2 \sin (\varepsilon) h
$$

Here $I$ is the interferometric path length, $\varepsilon$ is the elevation angle of the direct signal at the receiver and $h$ is the height difference between the receiver and the reflecting surface. Fig. 3 is generated based on the planar model for varying receiver altitudes. Obviously, the curves that illustrates the calculated interferometric path lengths can be easily distinguished for elevation angles close to the zenith. However, observations at high elevation angles are typically not coherent. At low elevation angles $\left(5^{\circ}\right.$ to $\left.30^{\circ}\right)$ the observations are coherent but it is difficult to distinguish the curves.

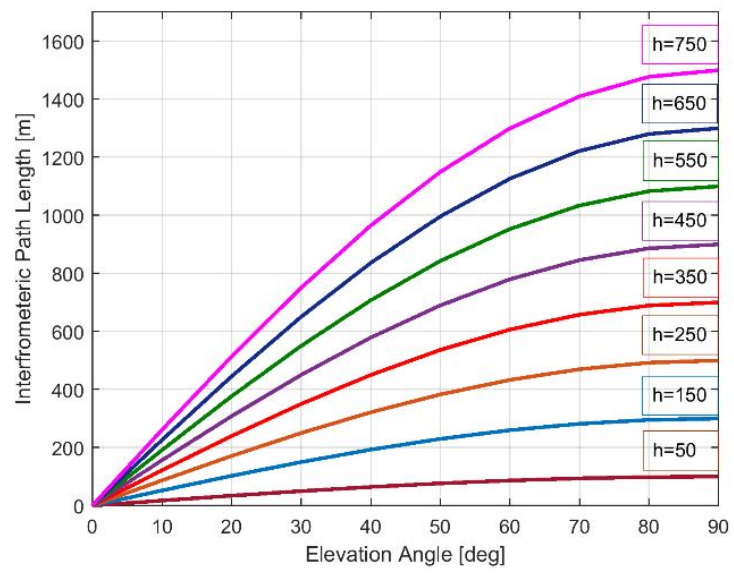

Figure 3: Interferometric path length, simulated by employing the planar model for different receiver heights (from 50 to $750 \mathrm{~m}$ ) in Godhavn. Distinguishing the observations at high elevation angles is simpler than at the low elevation angles.

Fig. 4 shows the differential interferometric path length for different sea level heights. It is generated based on Eq. 2.

$$
\Delta I=2 \sin (\varepsilon)\left(h-h_{0}\right)
$$

Where $\Delta I$ is the differential interferometric path length and $h_{0}$ is the height of receiver w.r.t reference level (e.g. MSL). Given some observations, water level fluctuations are more easy to distinguish close to the zenith than close to the horizon. The water level changes by $5 \mathrm{~cm}$. The upper and the lower curves show the water level change of $\pm 0.5 \mathrm{~m}$. At the elevation angle of $90^{\circ}$, for a water level difference of $\pm 0.5 \mathrm{~m}$, the differential interferometric path length equals $\pm 1 \mathrm{~m}$.

However, for the same situation at elevation angles of $30^{\circ}$ and $5^{\circ}$, the differential interferometric path lengths are about $\pm 0.5 \mathrm{~m}$ and $\pm 0.1 \mathrm{~m}$, respectively.

With decreasing elevation angles the direct and reflected signal paths through the troposphere increase. The longer the signal paths, the more the signal is affected by the troposphere and this effect is not taken into account by the simple planar model.

\section{THE PLANAR MODEL WITH TROPOSPHERIC CORRECTION}

The planar model with tropospheric correction can be written as (Cardellach, Fabra et al. 2011): 


$$
I=2 \sin (\varepsilon) h+T
$$

The first term is the planar model and the second term account for the troposphere.

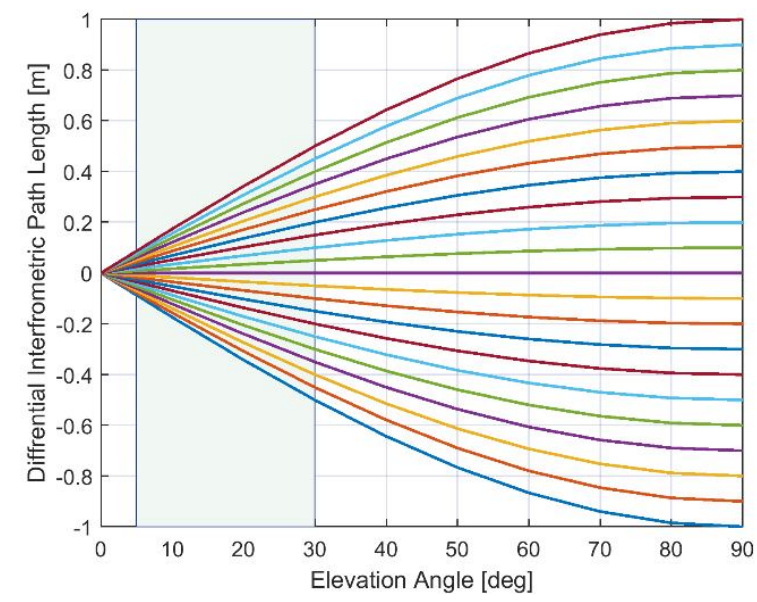

Figure 4: Differential interferometric path length, as a function of the elevation angle. Each curve attributes to a specific water height which is changing $5 \mathrm{~cm}$ by $5 \mathrm{~cm}$. For $\pm 0.5 \mathrm{~m}$ water surface fluctuation, there is $\pm 1 \mathrm{~m}$ interferometric path length change at the elevation angle of $90^{\circ}$ and much less at lower angles.

The tropospheric correction reads as (Fabra, Cardellach et al. 2012):

$$
T(\varepsilon)=2 \operatorname{STD}(\varepsilon)\left(e^{+\left(h / h_{\text {scale }}\right)}-1\right)
$$

The STD is the tropospheric delay for the direct signal at the station and $h_{\text {scale }}$ denotes a scale height chosen to be $7160 \mathrm{~m}$ (Fabra, Cardellach et al. 2012) in this study. The STD can be calculated through $S T D(\varepsilon)=Z H D m f_{h}(\varepsilon)+Z W D m f_{w}(\varepsilon)$ where $Z H D, Z W D$ are hydrostatic and wet zenith delays and $m f_{h}, m f_{w}$ are hydrostatic and wet mapping functions, respectively. In this study the Global Pressure and Temperature 2 Wet (GPT2w) model is utilized to compute the

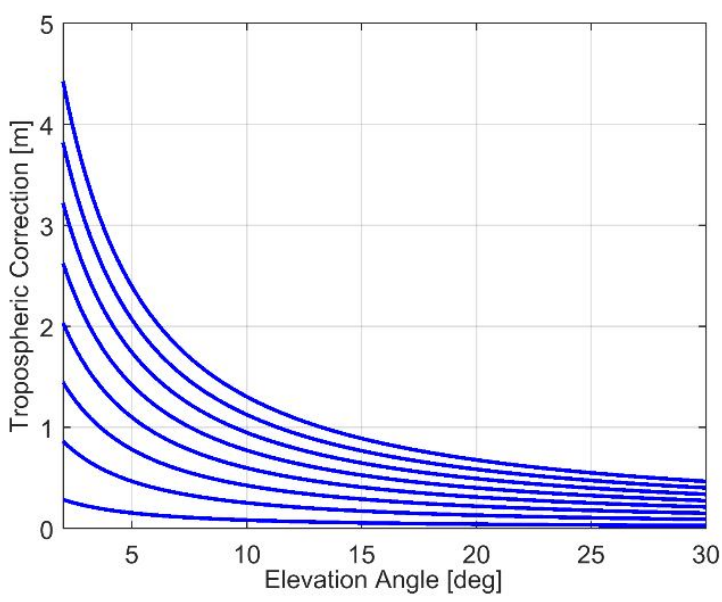

Figure 5: Tropospheric correction for different receiver altitudes. The lowest curve is for a receiver altitude of $50 \mathrm{~m}$ and the upper most curve is for a receiver of an altitude of $750 \mathrm{~m}$ (stepped by 100 $\mathrm{m})$. The hydrostatic and wet zenith delay and mapping function coefficients are taken from GPT $2 w$ model at Godhavn on 01.01.2009, 12.00 . The lower the elevation angle, the larger the troposphere correction. mapping functions (Böhm, Möller et al. 2015). The $Z H D, Z W D$ values are derived from a) climatological model (GPT2w) and b) a numerical weather model (NWM): the European Centre for Medium-Range Weather Forecasts (ECMWF) (Dee, Uppala et al. 2011).The estimated tropospheric correction, by the GPT2w model for various elevation angles and receiver altitudes, is shown in Fig. 5. The tropospheric effect cannot be neglected, especially at low elevation angles as the lower the elevation angle the larger the effect of the troposphere. Additionally, the higher the receiver, the larger the effect of the troposphere.

Fig. 6 shows the zenith total delay (ZTD) and the ZHD for a period of seven months (November 2008-May 2009) calculated from a NWM and the GPT2w climatology. As it is obvious, the difference between ZTD and ZHD at the case study (high latitudes) is ignorable.

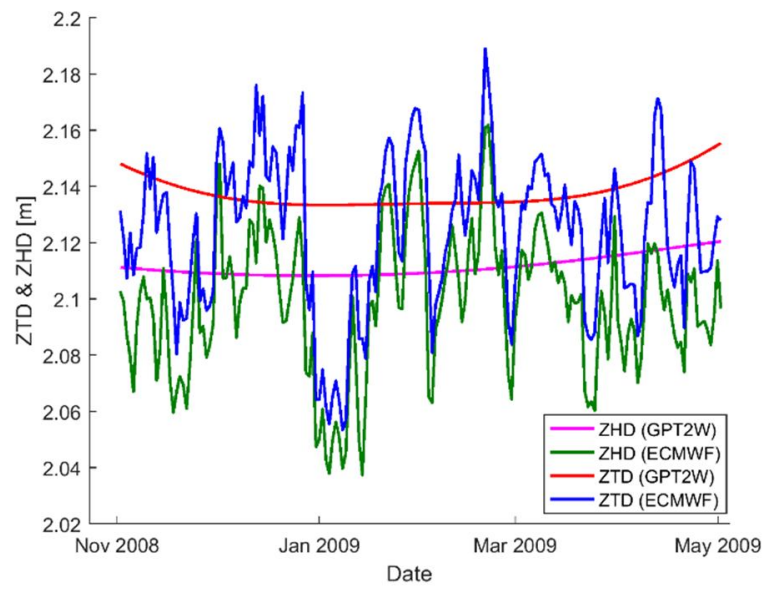

Figure 6: The zenith total delay and the zenith hydrostatic delay from GPT2W and ECMWF models at Godhavn. At lower latitudes, e.g., around equator, the wet troposphere would have bigger contribution because the water vapor content increases.

Table 1 summarizes the statistics, i.e., the fractional error of the climatology in terms of ZTD. In practice, slant total delay (STD) is typically approximated by $S T D(\varepsilon) \approx m f(\varepsilon) * Z T D$ where the mapping function is chosen to be the hydrostatic mapping function (Cardellach, Fabra et al. 2011).

\begin{tabular}{|l|l|}
\hline Uncertainty & $3.7[\%]$ \\
\hline Mean & $0.014[\mathrm{~m}]$ \\
\hline Standard Deviation (STD) & $0.028[\mathrm{~m}]$ \\
\hline Root Mean Square Error (RMSE) & $0.031[\mathrm{~m}]$ \\
\hline
\end{tabular}

Table 1: Comparing zenith total delay from ECMWF and GPT2W models. The ECMWF model is considered as the reference.

\section{THE RAY-TRACING MODEL}

This model represents a more realistic approach in comparison with the two previous models. Details on the ray-tracing model applied in this study can be found in (Semmling, Leister et al. 2016). To compare the accuracy of the models, the Model Accuracy (MA) is calculated through:

$$
M A=I_{M}(H=0)-I_{T}(H=0)
$$


Where $I_{T}$ is the true interferometric path length. Interferometric path lengths are computed at the reference reflecting surface $\mathrm{H}=0$ (e.g. MSL). $I_{M}$ denotes the computed interferometric path length from the respective model. The ray-tracing interferometric path model is considered as the truth. Fig. 7 shows MA for the planar model (top) and the planar model with tropospheric correction (bottom)

(1) Utilizing the planar model, does not allow to distinguish water level fluctuations of $0.5 \mathrm{~m}$ (top panel of Fig. 7).

(2) Utilizing the planar model with tropospheric correction using the mapping function and ZTD from the GPT2w. This model can be used for elevation angles above $30^{\circ}$ to detect $0.5 \mathrm{~m}$ water level fluctuations (bottom panel of Fig. 7).

(3) Utilizing the planar model with tropospheric correction using the mapping function from GPT2w and the ZTD from ECMWF. This model should be able to detect a $0.5 \mathrm{~m}$ water level changes at elevation angles above $12^{\circ}$ (bottom panel of Fig. 7).
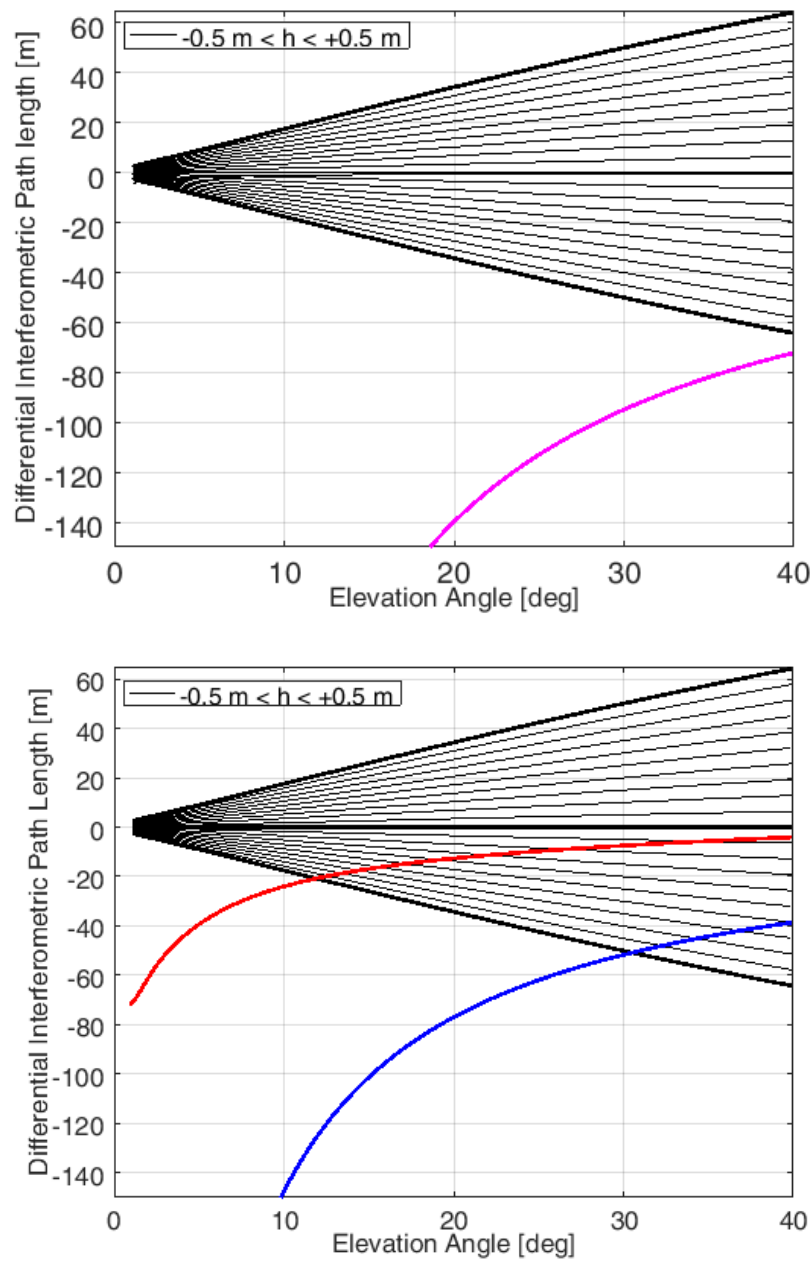

Figure 7: The model accuracy for the planar model (top panel) and the planar model with tropospheric correction (low panel). The purple curve shows the planar model accuracy without tropospheric correction. The blue and red curves show the planar model accuracy while the climatological and numerical ZTDs are used to calculate the tropospheric corrections, respectively. The black curves indicate the water height (h) that is changing $5 \mathrm{~cm}$ by $5 \mathrm{~cm}$.

Therefore, it can be concluded that employing the planar model should not be recommended. The planar model with tropospheric correction can be used at high elevation angles and low receiver altitudes. In the next section the accuracy of all three interferometric path models, using a phase and Doppler retrieval, are presented.

\section{SIMULATION OF INTERFEROMETRIC PATH}

In this section, the phase and Doppler observations are simulated based on the ray-tracing for 21 water level heights. Random noise is added. The phase observations include a phase ambiguity, which must be treated as an unknown parameter. The phase ambiguity estimation and its correlation to estimated water height fluctuation is the reason why we consider Doppler observations as well, despite increasing the noise (differentiating amplifies the noise). The interferometric path model is linearized.

$$
\begin{gathered}
I_{o b s}=I_{0}+\frac{\partial I}{\partial h} \delta h+A \\
D_{o b s}=D_{0}+\frac{\partial D}{\partial h} \delta h \\
D=\frac{d L}{d \sin (\varepsilon)}
\end{gathered}
$$
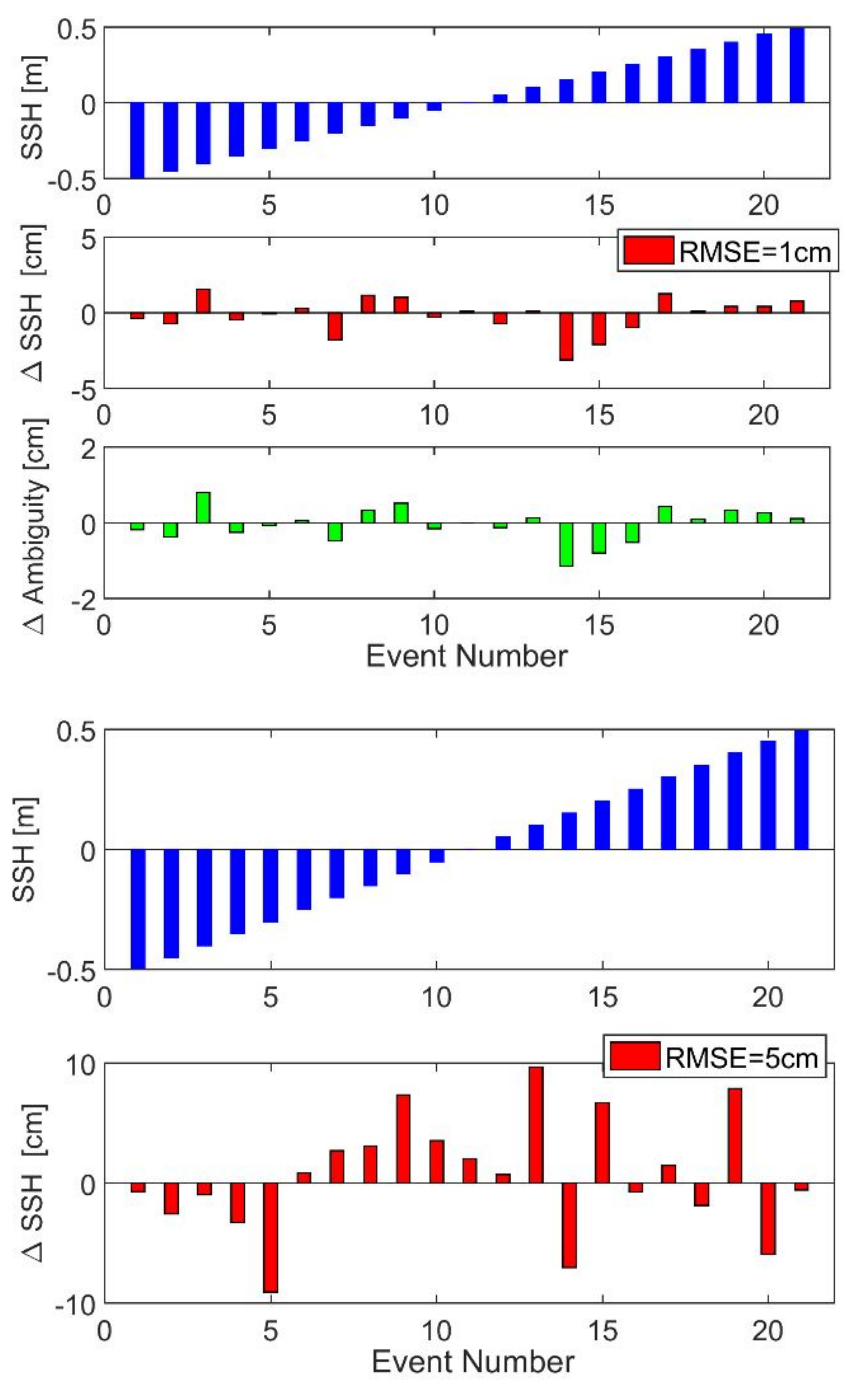
Figure 8: The employed interferometric path model is the raytracing model, phase retrieval (top panel) and Doppler retrieval (Bottom panel). The blue bars show the assumed Sea Surface Height (SSH). The red and green bars are the estimated water level and phase ambiguity differences. The observation accuracy is assumed to be $1 \mathrm{~cm}$. Observations are taken between $5^{\circ}$ and $15^{\circ}$.

$I_{o b s}$ is the phase observation, $I_{0}$ and $\frac{\partial I}{\partial h}$ are the modelled initial value and the partial differential of interferometric path length w.r.t. altitude, respectively. $\delta h$ is the altitude fluctuation and $A$ denotes the phase ambiguity. $D_{o b s}$ is the Doppler observation, $D_{0}$ and $\frac{\partial D}{\partial h}$ are the initial value and the partial differentiation of Doppler observation w.r.t. altitude, respectively. The Doppler observation is the differentiation of phase observation w.r.t. time $\left(\frac{\partial I}{\partial t}\right)$ but for simplicity we consider the partial derivative with respect to the elevation angle $\left(\frac{\partial I}{\partial \epsilon}\right)$ or to be more precise the partial derivative w.r.t. $\sin (\varepsilon)\left(\frac{\partial I}{\partial \sin (\varepsilon)}\right)($ Eq. 8)

As already described, in the case of interferometric path models, there are three choices, the planar model, the planar model with tropospheric correction and the ray-tracing model. In Fig. 8 (the ray-tracing model) and in Fig. 9 (the planar model with tropospheric correction) the altitude and phase ambiguity are estimated by employing the phase and the Doppler retrievals. As it is presented, the phase retrieval results 1 $\mathrm{cm}$ as RMSE by using the ray-tracing model and $437 \mathrm{~cm}$ when the planar model and GPT2W derived tropospheric correction is applied. By employing the Doppler retrieval, $5 \mathrm{~cm}$ and $467 \mathrm{~cm}$ are approached as RMSE by using the ray-tracing and the planar model with tropospheric correction, respectively. In these figures, the observations belong to elevation angles between $5^{\circ}$ to $15^{\circ}$ and the receiver altitude is $691.25 \mathrm{~m}$ w.r.t. MSL.

As it is obvious from the numerical results (see table 2), by employing the model based on ray-tracing, the best results are obtained. This model considers the ray bending and Earth curvature. Considering just the Earth curvature, cannot provide an accuracy of better than a few meters. The observation accuracy (noise) can affect the results especially when the Doppler retrieval is utilized. This is due to the fact that the Doppler retrieval noise is amplified. Another point about the planar model with tropospheric corrections is that it does not work sufficient for centimeter accuracy neither the ZTD is derived from NWMs nor blind models (BM). However, if the receiver altitude is low enough (about $100 \mathrm{~m}$ ) it can be employed. As was already indicated, that simple planar model is not recommended when decimal accuracy is required even at very low altitudes.
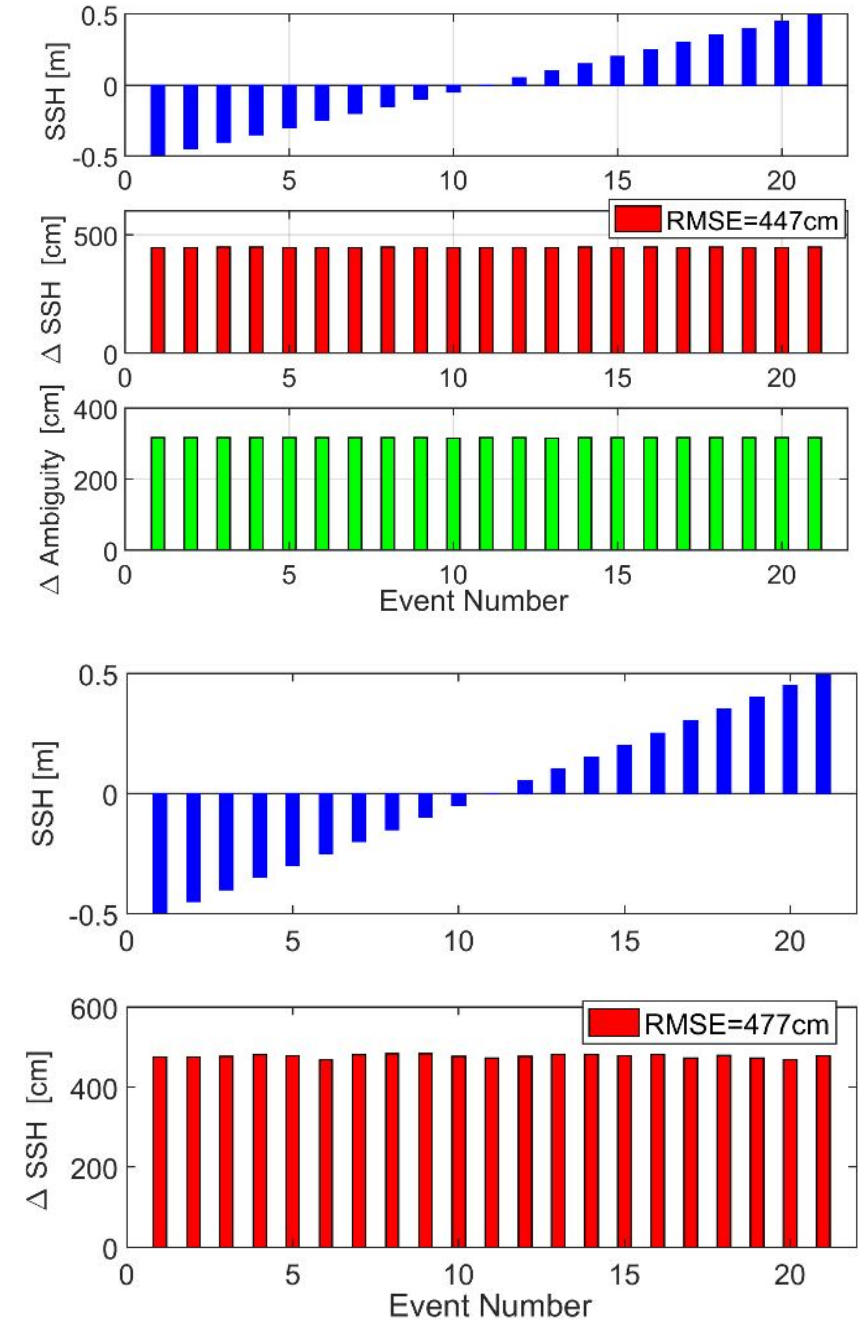

Figure 9: The employed model is the planar model with tropospheric correction derived from GPT2w model. Top panel: phase retrieval, bottom panel: Doppler retrieval. The observation accuracy is assumed to be $1 \mathrm{~cm}$. Observations are taken between $5^{\circ}$ and $15^{\circ}$.

\begin{tabular}{|c|c|c|c|c|c|c|c|c|}
\hline No. & $\begin{array}{l}\text { Geometry } \\
\text { Model }\end{array}$ & $\begin{array}{l}\text { Mapping } \\
\text { Function } \\
\text { Model }\end{array}$ & $\begin{array}{l}\text { ZTD } \\
\text { calculati } \\
\text { on } \\
\text { Source } \\
\end{array}$ & $\begin{array}{l}\text { Simulated } \\
\text { observation } \\
\text { accuracy } \\
{[\mathrm{cm}]}\end{array}$ & $\begin{array}{l}\text { Receiver } \\
\text { altitude } \\
{[\mathrm{m}]}\end{array}$ & $\begin{array}{l}\text { Elevation } \\
\text { angle } \\
\text { [deg.] }\end{array}$ & $\begin{array}{l}\text { RMSE } \\
\text { phase } \\
\text { retrieval } \\
{[\mathrm{cm}]}\end{array}$ & $\begin{array}{l}\text { RMSE } \\
\text { Doppler } \\
\text { retrieval } \\
{[\mathrm{cm}]} \\
\end{array}$ \\
\hline 1 & Planar & - & -- & 1 & 691.62 & $5-15$ & 822 & 879 \\
\hline 2 & Planar & -- & -- & 10 & 691.62 & $5-15$ & 822 & 861 \\
\hline 3 & Planar & -- & -- & 1 & 100.00 & $5-15$ & 108 & 117 \\
\hline 4 & $\begin{array}{l}\text { Planar with } \\
\text { tropospheric } \\
\text { correction }\end{array}$ & GPT2W & GPT2W & 1 & 691.62 & $5-15$ & 447 & 477 \\
\hline 5 & $\begin{array}{l}\text { Planar with } \\
\text { tropospheric } \\
\text { correction }\end{array}$ & GPT2W & GPT2W & 10 & 691.62 & $5-15$ & 439 & 480 \\
\hline 6 & $\begin{array}{l}\text { Planar with } \\
\text { tropospheric } \\
\text { correction }\end{array}$ & GPT2W & GPT2W & 1 & 100.00 & $5-15$ & 18 & 18 \\
\hline
\end{tabular}




\begin{tabular}{|c|c|c|c|c|c|c|c|c|}
\hline 7 & $\begin{array}{l}\text { Planar } \\
\text { with } \\
\text { tropospheric } \\
\text { correction } \\
\end{array}$ & GPT2W & ECMWF & 1 & 691.62 & $5-15$ & 428 & 459 \\
\hline 8 & $\begin{array}{l}\text { Planar } \\
\text { with } \\
\text { tropospheric } \\
\text { correction }\end{array}$ & GPT2W & ECMWF & 10 & 691.62 & $5-15$ & 430 & 440 \\
\hline 9 & $\begin{array}{l}\text { Planar } \\
\text { with } \\
\text { tropospheric } \\
\text { correction }\end{array}$ & GPT2W & ECMWF & 1 & 100.00 & $5-15$ & 22 & 24 \\
\hline 10 & Ray-Tracing & ---- & ECMWF & 1 & 691.62 & $5-15$ & 1 & 5 \\
\hline 11 & Ray-Tracing & $\begin{array}{l}--- \\
\end{array}$ & ECMWF & 10 & 691.62 & $5-15$ & 9 & 49 \\
\hline 12 & Ray-Tracing & --- & ECMWF & 1 & 100.00 & $5-15$ & 1 & 5 \\
\hline 13 & $\begin{array}{l}\text { Just } \\
\text { earth curvature } \\
\text { is considered }\end{array}$ & ----- & ----- & 1 & 691.62 & $5-15$ & 671 & 713 \\
\hline 14 & $\begin{array}{l}\text { Just } \\
\text { earth curvature } \\
\text { is considered }\end{array}$ & ----- & ------ & 10 & 691.62 & $5-15$ & 674 & 699 \\
\hline 15 & $\begin{array}{l}\text { Just } \\
\text { earth curvature } \\
\text { is considered }\end{array}$ & ----- & ------ & 1 & 100.00 & $5-15$ & 105 & 113 \\
\hline
\end{tabular}

Table 2: Numerical results of employing different models in different conditions of receiver altitude and observation accuracy. All the simulations refer to Godhavn on the 01.01.2009.

using the planar model even if the the accuracy of the observations is $1 \mathrm{~cm}$ and the receiver altitude is $100 \mathrm{~m}$ is not recommended. Maybe for the receivers with altitudes of a few meters (e.g. the GNSS tide gauges) this model can be utilized. Using the planar model with tropospheric correction is appropriate for the receivers with a few hundred meter altitude. In such situation, the accuracy of a few decimeter is expected.

\section{CONCLUSION}

In this study, three interferometric path models, the planar model, the planar model with tropospheric correction and the ray-tracing model are studied at a station in North Greenland. Interferometric path lengths ( difference between the direct and the reflected signal paths) are computed and noise is added to mimic observation errors. The raytracing model is as to expect, the best option. It provides about $1 \mathrm{~cm}$ and $5 \mathrm{~cm}$ as RMSE while the phase and the Doppler retrievals are utilized to estimate sea surface height, respectively. The simulated phase observation accuracy is assumed as $1 \mathrm{~cm}$ and the elevation angle is $5^{\circ}$ to $15^{\circ}$. The planar model cannot be used if decimeter level changes should be detectable. The planar model with tropospheric correction is appropriate for some applications when elevation angles are above $15^{\circ}$ and/or the receiver altitude does not exceed $100 \mathrm{~m}$. To detect a decimeter water level fluctuation, while employing the $m f$ from the GPT2w and ZTD derived from numerical weather models, the elevation angle of the observations should be above about $25^{\circ}$.

\section{ACKNOWLEDGEMENTS}

We would like to express our sincere appreciation to ECMWF for providing the numerical weather model. We are very grateful to Jens Wickert, Florian Zus and Maximilian Semmling at GFZ for their essential advice.

\section{REFERENCES}

Bilich, A., K. M. Larson and P. Axelrad (2004). "Observations of signal-to-noise ratios (SNR) at geodetic GPS site CASA: Implications for phase multipath." Proceedings of the Centre for European Geodynamics and Seismology 23: 77-83.

Böhm, J., G. Möller, M. Schindelegger, G. Pain and R. Weber (2015). "Development of an improved empirical model for slant delays in the troposphere (GPT2w)." GPS Solutions 19(3): 433-441.

Cardellach, E., F. Fabra, O. Nogués-Correig, S. Oliveras, S. Ribó and A. Rius (2011). "GNSS-R ground-based and airborne campaigns for ocean, land, ice, and snow techniques: Application to the GOLD-RTR data sets." Radio Science 46(6).

Dee, D. P., S. M. Uppala, A. Simmons, P. Berrisford, P. Poli, S. Kobayashi, U. Andrae, M. Balmaseda, G. Balsamo and d. P. Bauer (2011). "The ERA-Interim reanalysis: Configuration and performance of the data assimilation system." Quarterly Journal of the royal meteorological society 137(656): 553-597.

Fabra, F., E. Cardellach, A. Rius, S. Ribo, S. Oliveras, O. NoguésCorreig, M. B. Rivas, M. Semmling and S. D'Addio (2012). "Phase altimetry with dual polarization GNSS-R over sea ice." IEEE Transactions on Geoscience and Remote Sensing 50(6): 2112-2121.

Helm, A. (2008). "Ground-based GPS altimetry with the L1 OpenGPS receiver using carrier phase delay observations of reflected GPS signals." Scientific Technical Report/Geoforschungszentrum Potsdam.

Khajeh, S., I. Jazireeyan and A. A. Ardalan (2014). "Applying satellite altimetry to wetland water levels monitoring (case study: Louisiana wetland)." IEEE Geoscience and Remote Sensing Letters 11(9): 14751478 .

Löfgren, J. S., R. Haas and J. M. Johansson (2011). "Monitoring coastal sea level using reflected GNSS signals." Advances in Space Research 47(2): 213-220. 
Lowe, S. T., C. Zuffada, Y. Chao, P. Kroger, L. E. Young and J. L. LaBrecque (2002). "5-cm-Precision aircraft ocean altimetry using GPS reflections." Geophysical Research Letters 29(10).

Martin-Neira, M. (1993). "A passive reflectometry and interferometry system (PARIS): Application to ocean altimetry." ESA journal 17(4): 331-355.

Martin-Neira, M., M. Caparrini, J. Font-Rossello, S. Lannelongue and C. S. Vallmitjana (2001). "The PARIS concept: An experimental demonstration of sea surface altimetry using GPS reflected signals." IEEE transactions on geoscience and remote sensing 39(1): 142-150.

Roussel, N., F. Frappart, G. Ramillien, J. Darrozes, C. Desjardins, P. Gegout, F. Pérosanz and R. Biancale (2014). "Simulations of direct and reflected wave trajectories for ground-based GNSS-R experiments." Geoscientific Model Development 7: 2261-2279.

Ruffini, n. G., F. Soulat, M. Caparrini, O. Germain and M. MartínNeira (2004). "The Eddy Experiment: Accurate GNSS-R ocean altimetry from low altitude aircraft." Geophysical research letters 31(12).

Semmling, A. M., G. Beyerle, R. Stosius, G. Dick, J. Wickert, F. Fabra, E. Cardellach, S. Ribó, A. Rius and A. Helm (2011). "Detection of Arctic Ocean tides using interferometric GNSS-R signals." Geophysical Research Letters 38(4).
Semmling, A. M., V. Leister, J. Saynisch, F. Zus, S. Heise and J. Wickert (2016). "A phase-altimetric simulator: Studying the sensitivity of Earth-reflected GNSS signals to ocean topography." IEEE Transactions on Geoscience and Remote Sensing 54(11): 67916802 .

Semmling, A. M. (2012). Altimetric monitoring of Disko Bay using interferometric GNSS observations on L1 and L2, Berlin, Techn. Univ., Diss., 2012.

Treuhaft, R. N., S. T. Lowe, C. Zuffada and Y. Chao (2001). "2-cm GPS altimetry over Crater Lake." Geophysical Research Letters 28(23): 4343-4346.

Wickert, J., E. Cardellach, M. Martín-Neira, J. Bandeiras, L. Bertino, O. B. Andersen, A. Camps, N. Catarino, B. Chapron and F. Fabra (2016). "GEROS-ISS: GNSS reflectometry, radio occultation, and scatterometry onboard the international space station." IEEE Journal of selected topics in applied Earth observations and Remote Sensing 9(10): 4552-4581. 